\title{
Production control and supplier selection under demand disruptions
}

\author{
Xianzhe Chen, Jun Zhang \\ North Dakota State University (UNITED STATES) \\ xianshe.chen@ndsu.edu; jun.zhang@,ndsu.edu
}

Received March 2010

Accepted September 2010

\begin{abstract}
This paper investigates the effects of demand disruptions on production control and supplier selection in a three-echelon supply chain system. The customer demand is modeled as a jump-diffusion process in a continuous-time setting. A two-number production-inventory policy is implemented in the production control model for the manufacturer. The objective is to minimize the long-term average total cost consisting of backlog cost, holding cost, switching cost, and ordering cost. The simulated annealing method is applied to search the optimal critical switching values. Furthermore, an improved analytical hierarchy process (AHP) is proposed to select the best supplier, based on quantitative factors such as the optimal long-term total cost obtained through the simulated annealing method under demand disruptions and qualitative factors such as quality and service. Numerical studies are conducted to demonstrate the effects of demand disruptions in the face of various risk scenarios. Managerial insights from simulation results are provided as well. Our approaches can be implemented as the "stress test" for companies in front of various supply chain disruption scenarios.
\end{abstract}

Keywords: supplier selection, demand disruption, simulated annealing, jump diffusion process, analytical hierarchy process 


\section{Introduction}

Although demand disruptions happen infrequently, they have significant impacts on the whole supply chain (Tang, 2006). In 2008, many manufacturers experienced the global financial crisis and sudden demand disruptions. Some of the manufacturers who could not adapt to the sudden economic change by adopting alternative supplier selection and production control strategies had to shut down their businesses. For instance, nearly 1000 toy manufacturers closed down in Southern China in 2008 because of the nosedived overseas orders from U.S. and Europe. Hendricks and Singhal (2005) find that the average abnormal stock returns of firms which experienced disruptions are almost $-40 \%$, which clearly shows that the supply chain disruptions could significantly affect the normal operation and financial health of a company. Hence, the main purpose of this paper is to investigate the performance of a three-echelon supply chain system under demand disruptions in a continuous-time setting, to discuss production control and optimal supplier selection problems under demand disruptions, and to provide managerial insights on the demand disruptions through numerical studies.

Production control and supplier selection are important decisions for the manufacturers to make in order to maintain low cost and high quality products and to be successful in the competition. Production control is used to determine the optimal timing and amount to produce so that manufacturers can match the demand to the supply with the lowest operation cost. Little research has considered optimal production control under demand disruptions. Supplier selection problems have been widely studied in literature, but most of the research focuses on selecting the suppliers only based on their performances. Little research has been conducted to evaluate the suppliers when the manufacturers face demand disruptions. We believe that demand disruptions will impact the result of supplier selection of the manufacturers. Even less research considers production control and supplier selection simultaneously under demand disruptions. In our study, we find that the optimal production control policy for different suppliers varies under different demand scenarios. We propose a stochastic framework to determine the optimal production control policy and supplier selection procedure for a manufacturer that is in a three-echelon supply chain setting consisting of suppliers, one manufacturer, and customers under demand disruptions. The proposed supplier selection procedure is aimed at selecting the best supplier based on not 
only suppliers' performances but also the characteristics of the customer demand disruptions. Numerical case studies of this procedure are provided.

The rest of this paper is organized as follows: Section 2 reviews the relevant literature. Model development is shown in Section 3. Section 4 proposes the solution procedures for production control and supplier selection problems under demand disruptions. Sensitive analysis is discussed in Section 5. Finally, Section 6 draws the conclusion.

\section{Literature review}

Since the supplier selection process involves many different categories such as purchasing, quality, delivery and production, it is a multi-objective problem which includes quantitative and qualitative criteria. There are several common approaches in the literature used to evaluate suppliers, such as the analytic hierarchy process (AHP) and the total cost of ownership (TCO). AHP is used in multiple criteria decision-making environments where price is not the only factor, while TCO considers many other purchasing relevant costs besides the purchasing price. There are also some traditional optimization techniques that are used to solve supply chain problems such as dynamic programming and quadratic programming, but these optimization algorithms may obtain local optimal solutions. Hence, some simulation optimization methods such as genetic algorithm and simulated annealing are used to avoid local optimal solution. Table 1 summarizes typical methods used in supplier selection literature and the corresponding representative papers.

Little research has been conducted in supplier selection under supply chain disruptions. Tang (2006) classifies supply chain risks into two categories: operational risk and disruption risk. Chopra and Sodhi (2004) categorize supply chain risks into nine parts: 1) disruptions 2) delays 3) systems 4) forecast 5) intellectual property 6) procurement 7) receivables 8) inventory and 9) capacity. In this paper, we divide the supply chain risks into two groups: inherent and disruption risks. The inherent risk refers to the organizational intrinsic uncertainty such as uncertain lead time, while disruption risk refers to natural disruptions, i.e. earthquakes, or man-made disruptions caused by terrorism attacks. 


\begin{tabular}{|c|c|c|c|}
\hline $\begin{array}{c}\text { Supplier selection } \\
\text { methods }\end{array}$ & Advantage & Disadvantage & References \\
\hline $\begin{array}{c}\text { Total cost of } \\
\text { ownership (TCO) }\end{array}$ & $\begin{array}{c}\text { Better for organizations to } \\
\text { understand and mange } \\
\text { their costs }\end{array}$ & $\begin{array}{c}\text { The amount of } \\
\text { complexity and the } \\
\text { data requirement }\end{array}$ & $\begin{array}{c}\text { Degraeve and } \\
\text { Roodhooft (1999), } \\
\text { Smytka and Clemens } \\
\text { (1993) }\end{array}$ \\
\hline $\begin{array}{c}\text { Analytic hierarchy } \\
\text { process (AHP) }\end{array}$ & $\begin{array}{c}\text { Consider both quantitative } \\
\text { and qualitative factors }\end{array}$ & $\begin{array}{c}\text { Difficult to take into } \\
\text { account constraints }\end{array}$ & $\begin{array}{c}\text { Bhutta and Huq } \\
\text { (2002) }\end{array}$ \\
\hline $\begin{array}{c}\text { Multi-objective } \\
\text { programming (MOP) }\end{array}$ & $\begin{array}{c}\text { Provide suggested } \\
\text { allocation volume for each } \\
\text { supplier }\end{array}$ & $\begin{array}{c}\text { Complex, in some } \\
\text { cases impractical to } \\
\text { implement }\end{array}$ & $\begin{array}{c}\text { Cakravastia and } \\
\text { Takahashi (2004), } \\
\text { Narasimhan and } \\
\text { Talluri (2006), Chan } \\
\text { (2003) }\end{array}$ \\
\hline $\begin{array}{c}\text { Simulation } \\
\text { optimization }\end{array}$ & $\begin{array}{c}\text { Use for both qualitative } \\
\text { and quantitative attributes, } \\
\text { avoid local optimal solution }\end{array}$ & $\begin{array}{c}\text { Time consuming, } \\
\text { difficult to take into } \\
\text { account subjective } \\
\text { criteria }\end{array}$ & $\begin{array}{c}\text { Ding, Benyoucef and } \\
\text { Xie (2005), Haq and } \\
\text { Kannan (2006) }\end{array}$ \\
\hline
\end{tabular}

Table 1. "Comparison of supplier selection methods".

Lee, Padmanabhan and Whang (1997) investigate the bullwhip effect in a supply chain and analyze four sources of the bullwhip effects. Furthermore, Lee, So and Tang (2000) discuss the information sharing in a two-echelon supply chain with non-stationary end demand. Qi, Bard and Yu (2004) analyze the supply chain coordination with demand disruption in a deterministic scenario. Song and Zipkin (1996) consider the inventory control under supply breakdown by modeling the system as a discrete-time Markov process. Tomlin (2006) studies a single-product case in which a firm can source from two suppliers - one unreliable and one reliable which is more expensive. Most of the research either are based on discrete time setting or consider only inherent risk. Bather (1966) is the first one to consider a one-product inventory model where the demand follows the Wiener process. Inspired by this paper, a variety of extensions and discussions followed this direction. Puterman (1975) investigates a continuous-time stochastic storage model which assumes the two-number inventory policy. Harrison and Taylor (1978) explicitly compute an optimal policy for the two-number inventory policy in a diffusion setting. A review about deterministic and stochastic control theory is given by Neck (1984). Bar-Lev, Parlar and Perry (1993) analyze the Brownian inventory system with supplier uncertainty by using impulse control. An explicit formula of the expected total discounted cost for an infinite time horizon is proposed by Dohi, Kaio and Osaki (1993). Beyer (1994) presents a special oneproduct inventory model by using the Wiener demand process with a fixed positive lead time and a ( $r$, Q) strategy. Duncan, Parsik-Duncan and Zhang (1999) 
implement adaptive control for stochastic manufacturing systems with hidden Markovian demands and small noise. However, little research investigates both the inherent and disruption supply chain risks. Therefore, our research is motivated to model the supply chain risk which includes both inherent and disruption risks by using a jump-diffusion model. We also investigate the effects of demand disruptions on production control and the performance of supply chain and on the decision for supplier selection problems.

\section{Model development}

In this paper, the following assumptions are made. First of all, the manufacturer's demand is modeled as a jump-diffusion process which consists of the normal demand fluctuations and occasional demand disruptions. The jump-diffusion process has already been applied in other areas, such as finance and economics, to describe the normal price volatility and sudden price jumps (Kou, 2002). The demand disruptions in a continuous-time setting have similar characteristics as price disruptions. The Wiener process that is the counterpart of white noise in a discrete-time setting represents the normal dynamics of demand and the jump process is used to demonstrate the significant impact of the outside information release or sudden economic changes on demand.

Secondly, we consider varied jump sizes coming from a Laplace distribution, which contains some favorable property such as leptokurtic (Kou, 2002). Thirdly, a ( $r, Q$ ) ordering policy is adapted to model the replenishment decision from suppliers. The basic mechanism of the $(r, Q)$ model is that when the inventory position reaches the reorder point $r$, a replenishment order of quantity $Q$ is placed. Fourthly, we assume that it will consume one unit of raw material to produce one unit of product.

Finally, a two-number inventory policy that is proved to be optimal in a diffusion model (Vickson, 1986) is searched by simulated annealing method and implemented for the manufacturer to make production decisions. The mechanism of this policy is that 1 ) when the inventory level $x_{t}$ of the finished products at time $t$ is less or equal to $x_{0}$, where $\mathrm{x} 0$ is a lower bound, then a machine which is off at time $t$ will be turned on instantaneously; 2) when the inventory level $x_{t}$ is greater or equal to $x_{1}$, where $\mathrm{x} 1$ is an upper bound, then the machine which is on at time $\mathrm{t}$ 
will be turned off; 3) when the inventory level is between the lower bound and upper bound, i.e. $x_{0}<x_{t}<x_{1}$, then the machine will keep the previous status. If the status of the machine is switched, then it will cause a switching cost. Graves and Keilson (1981) prove this two-number inventory policy to be optimal in discretetime as well. However, the method used to find the critical values of $x 0$ and $x 1$ in the diffusion process cannot be applied to find the optimal values in the jumpdiffusion scenario. Hence, a heuristic searching algorithm, simulated annealing (SA), is implemented to find the critical values for the jump-diffusion process.

In the following sub-sections, we present several relevant components about jumpdiffusion model. Firstly, the Wiener process and its generalized form are introduced. Secondly, the zero-one jump law used to generate jumps in the simulation is presented. Lastly, the model is proposed and discussed.

\subsection{Wiener process}

In a discrete-time time series model, the shocks are assumed to form a white noise process that is not predictable. The counterpart of shocks in a continuous-time model is the increments of a Wiener process which is also called a standard Brownian motion. If we focus on small change $\Delta w_{t}=w_{t+\Delta t}-w_{t}$ associated with a small increment $\Delta t$ in time, then a continuous time stochastic process $\left\{w_{t}\right\}$ is a Wiener process if it satisfies:

1) $\Delta w_{t}=\varepsilon \sqrt{\Delta t}$, where $\varepsilon$ is a standard normal random variable and $\Delta w_{t} \sim N(0, \Delta t)$;

2) $\Delta w_{t}$ is independent of $w_{j}$ for all $j \leq t$.

The Wiener process is a special stochastic process with 0 drift and variance proportional to the length of time intervals, which means that the mean of the change rate is 0 and the variance of the change rate is 1 . The generalized Wiener process is a stochastic process whose drift has a nonzero rate $\mu$ and the variance of the change rate is $\sigma^{2}$. Denote the generalized Wiener process by $x_{t}$ and use the notation dy for a small change in variable $y$. Then the generalized Wiener process for $\mathrm{x}_{\mathrm{t}}$ is $d x_{t}=\mu d t+\sigma d w_{t}$, where $\mathrm{w}_{\mathrm{t}}$ is a Wiener process. 


\subsection{Zero-one jump law}

According to Hanson (2007), the jump process should follow the zero-one jump law, which will be implemented in the later simulation program. Let $d t>0$ and $\lambda$ be positive and bounded, then we have

1) $\operatorname{Prob}[d P(t)=0]=1-\lambda d t$;

2) $\operatorname{Prob}[d P(t)=1]=\lambda d t$;

3) $\operatorname{Prob}[d P(t)>1]=0$;

Equation 1. "Zero-one jump law".

where $P(t)$ denotes the jump process with a fixed jump rate $\lambda$ and $d P(t)$ represents the differential in $P(t)$ which implies that any jump will be captured in $d P(t)$. The first two properties represent that as the jump rate increases, the probability that a jump occurs increases accordingly. Property (3) implies that in any particular dP(t) the number of jumps will not exceed 1 . These rules will be implemented in the later simulation study to generate jumps.

\subsection{Proposed model}

\begin{tabular}{|c|c|}
\hline Notation & Description \\
\hline $\mathrm{x}_{\mathrm{t}}$ & the finished products inventory level at time $\mathrm{t}$ \\
\hline $\mathrm{y}_{\mathrm{t}}$ & the raw material inventory level at time $\mathrm{t}$ \\
\hline $\mathrm{Q}$ & the production rate at time $\mathrm{t}$ \\
\hline$\mu$ & the demand rate at time $\mathrm{t}$ \\
\hline$\sigma^{2}$ & the variance in demand per unit time \\
\hline$w_{t}$ & the standard wiener process \\
\hline $\mathrm{P}$ & the unit backlog penalty cost \\
\hline $\mathrm{H}$ & the unit holding cost \\
\hline $\mathrm{K}$ & the production switching cost per time \\
\hline $\mathrm{B}$ & the ordering cost per time \\
\hline $\mathrm{T}$ & the time length \\
\hline $\mathrm{X}_{0}$ & the initial finished inventory level \\
\hline $\mathrm{Y}_{0}$ & the initial raw material inventory level \\
\hline $\mathrm{S}\left(\mathrm{x}_{\mathrm{t}}\right)$ & the average production switching cost \\
\hline $\mathrm{C}\left(\mathrm{x}_{\mathrm{t}}\right)$ & inventory/penalty cost rate at time $\mathrm{t}$ \\
\hline $\mathrm{G}\left(\mathrm{x}_{\mathrm{t}}\right)$ & ordering cost from supplier at time $\mathrm{t}$ \\
\hline $\mathrm{mode}(\mathrm{t})$ & the machine state at time $\mathrm{t}$ \\
\hline $\mathrm{J}$ & the compound Poisson process with intensity $\lambda$ and magnitude $v$ \\
\hline $\mathrm{G}$ & the long-term average cost \\
\hline
\end{tabular}

Table 2. "Notations". 
The jump-diffusion process has been used to model the normal price volatility and sudden price jump in finance and economics areas (Kou, 2002). In this paper customer demand is modeled as a jump-diffusion process, which includes both the normal balances between supply and demand and sudden changes due to external extreme events, such as significant information released about products, manmade disasters or natural disasters. We model the customer demand as a jumpdiffusion process as follows:

$$
d D_{t}=\mu d t-\sigma d w_{t}-d J
$$

Equation 2. "Demand model with jump process".

where $D t$ is the demand at time $t$ and notations for other variables are shown in Table 2. The goal is to determine the optimal critical values for the two-number inventory-production control policy in order to minimize the expected total cost including inventory holding cost and backlog cost (i.e. the inventory level $<0$ ), machine switching cost and ordering cost. Note that production cost is not considered in this paper, since it will not affect the final results according to Vickson (1986). The objective function is

$$
\min E\left\{\int_{0}^{T} C\left(x_{t}\right) d t+S\left(x_{t}\right)+G\left(y_{t}\right)\right\}
$$

Equation 3. "Objective function".

where $\left(x_{t}\right)=\left\{\begin{array}{ll}-p x_{t} & \text { if } x_{t}<0 \\ h x_{t} & \text { if } x_{t}>0\end{array}\right.$. The state equation follows an Itô stochastic differential equation, which is called a jump-diffusion process:

$$
\begin{gathered}
d x_{t}=I(\operatorname{mode}(t)>0) q d t-d D_{t} \\
=(I(\operatorname{mode}(t)>0) q-\mu) d t+\sigma d w_{t}+d J
\end{gathered}
$$

Equation 4. "Inventory level with jump process".

where I(.) is an indicator function when the inside condition is true, then the value is 1 , otherwise $0 ; \operatorname{mode}(t)$ is the machine state, when the machine is on at time $t$, then $\operatorname{mode}(t)=1$; when the machine is off at time $t, \operatorname{mode}(t)=0$. In our study, because the supply condition is integrated in the whole supply chain, the twonumber inventory policy has additional constraints: the machine will be turned off 
if it is on at time $t$ when the raw material inventory yt level is zero, which means the manufacturer runs out of raw material and cannot continue producing. Hence, mode $(t)$ 's value can be updated continuously by the following function:

$$
\operatorname{mode}(t+\Delta t)=\left\{\begin{array}{cc}
1, & \text { if } \operatorname{mode}(t)=0 \text { and } x_{t} \leq x_{0} \text { and } y_{t}>0 \\
1, & \text { if mode }(t)=1 \text { and } x_{t}<x_{1} \text { and } y_{t}>0 \\
0, & \text { otherwise }
\end{array}\right.
$$

Equation 5. "Machine mode representation".

where $\Delta t$ is a small increment of time. Therefore, $S\left(x_{t}\right)=\mathrm{k} * \mid$ changes in mode|, where | | denotes the cardinal number, which is the number of changes in machine modes.

Whenever the raw material inventory level yt is less than $r$, an order of quantity $Q$ is placed by the manufacturer to replenish the raw material inventory. Hence, $G\left(y_{t}\right)=b * \mid$ ordering|, where |ordering| denotes the number of times that the manufacturer places the orders with its supplier.

Our objective is to determine the optimal production control values $x_{0}$ and $x_{1}$ in order to minimize the expected total cost described in Equation 3. Unfortunately, there is no closed-from for $x_{0}$ and $x_{1}$, therefore, the optimal values of $x_{0}$ and $x_{1}$ are searched by using the simulated annealing algorithm, which is discussed in the next section.

\section{Proposed solution procedure}

A simulation optimization procedure is developed to find the optimal values of $x_{0}$ and $x_{1}$ and evaluate the effects of demand disruptions on the supplier selection. An improved analytic hierarchy process (AHP) is implemented to select the best supplier by considering quantitative factors, such as expected total cost obtained from simulation optimization, and qualitative factors, such as quality and service. The structure of this section is as follows. Firstly, simulated annealing is introduced in Section 4.1. Secondly, simulation parameters are represented in Section 4.2. Thirdly, numerical results of the effects of demand disruption on the whole supply chain are discussed in Section 4.3. Fourthly, the supplier selection problem under demand disruption is investigated in Section 4.4. Lastly, a numerical case study of supplier selection is presented by using the improved AHP in Section 4.5. 


\subsection{Simulated annealing}

Simulated annealing (SA) is a heuristic-search method which is analogous as the way a metal cools and freezes into a minimum energy crystalline structure - that is the annealing process - and searches for a minimum in a more general system. The major advantages of SA are 1) the ability to deal with arbitrary systems and cost functions; 2) statistical guarantee to converge to an optimal solution; 3 ) the ability to code easily even for complex problems; 4) the ability to avoid becoming trapped in the local minima/maxima and 5) the general ability to give a "good" solution. The original idea is proposed by Kirkpatrick, Gelatt and Vecchi (1983), who develop the similarities between statistical mechanics and combinatorial optimization and then apply it to a number of problems in optimal design of computers. Currently, SA has been widely used in many optimization problems (Suman \& Kumar, 2006).

In order to avoid being trapped in the local minima, the upward moves of the cost (the moves that worsen the solution) are accepted with a probability determined by the Metropolis function $\left(\mathrm{e}^{-\Delta \mathrm{C} / \mathrm{T}}\right)$, where $\Delta \mathrm{C}$ denotes the cost change of moves. As $\mathrm{T}$, the temperature, decreases, the probability of acceptance of the upward moves decreases. The initial temperature needs to be high so that it can find the global optimal solutions, but not too high since it will lead to a long processing time. To determine a good value of initial temperature, a sequence of random moves can be performed and the average cost change in upward moves is computed before the start of the actual SA procedure. The Metropolis function $\left(\mathrm{e}^{-\Delta \mathrm{C} / \mathrm{T}}\right)$ is then used to determine the initial value of T (Youssef, Sait, \& Adiche, 2001). The average cost change in upward moves is given as:

$$
\Delta C_{u}=\frac{1}{M_{u}} \sum_{i=1}^{M_{u}} \Delta C_{i}
$$

Equation 6. "Average cost change in upward moves".

where $\mathrm{Mu}$ denotes the number of moves that worsen the solution (upward moves) and $\Delta C_{i}$ is the cost change of each upward move $\mathrm{i}$. Hence, the initial value of $\mathrm{T}$ can be estimated as: 


$$
T_{0}=\frac{\Delta C_{u}}{\ln \left(P_{0}\right)}
$$

Equation 7. "I nitial temperature value".

where $P_{0}$ is the probability of accepting the upward moves. If we accept the upward moves with the probability of 0.5 , then $P_{0}$ is set as 0.5 . The simulated annealing algorithm is implemented as follows:

1) Choose a random design vector $X_{i}=\left(x_{0}^{i}, x_{1}^{i}\right)$, where $\left(x_{0}^{i}, x_{1}^{i}\right)$ refers to the twonumber inventory policy at state $i$. Select the initial temperature, and then specify the annealing schedule, i.e. temperature reduction ratio, number of iterations before temperature reduction, etc.

2) Evaluate $F\left(X_{i}\right)$ by a simulation model, where $F\left(X_{i}\right)$ denotes the objective function value when the design vector is $X_{i}$.

3) Adjust step length to obtain a new neighboring design vector $X_{i+1}$

4) Evaluate $F\left(X_{i+1}\right)$ by a simulation model.

5) If $\mathrm{F}\left(\mathrm{X}_{\mathrm{i}+1}\right)<\mathrm{F}\left(\mathrm{X}_{\mathrm{i}}\right)$, i.e. $F\left(X_{i+1}\right)-F\left(X_{i}\right)=\Delta C<0$, then $X_{i+1}$ is the new current solution.

6) If $F\left(X_{i+1}\right)>F\left(X_{i}\right)$, then accept $X_{i+1}$ as the new current solution with probability $\mathrm{e}^{-\Delta \mathrm{C} / \mathrm{T}}$.

7) Reduce the temperature according to the annealing schedule.

8) Terminate the algorithm if the terminating criteria satisfy, otherwise go back to step 3).

Here, $F\left(X_{i}\right)=\sum_{j=1}^{N} V_{j}\left(X_{i}\right) / N, \mathrm{Vj}$ is the total cost at sampling $\mathrm{j}$ for design vector $\mathrm{Xi}$, and $\mathrm{N}$ is the number of samplings. In our study, the function $F\left(X_{i}\right)$ refers to Equation 3.

\subsection{Simulation parameters}

This model consists of two parts, with the first part being a diffusion process and the second part being a jump process. The occurrences of jump are governed by a 
Poisson process and the jump size follows a Laplace distribution. Although the problem is studied in a continuous time setting, we discretize the time into small intervals. In our simulation study, the total time length is 4500 units and divided into 10,000 intervals, thus the small increment of time $\Delta t=4500 / 10000$. The variance of the process can be computed as $\sigma^{2} \Delta t=1.8 *(4500 / 10000)=0.81$. We set the intensity of the Poisson process to be $1 \%$, that is, if the time length is 4500 units, then there will be 45 jumps during the period, which is consistent with the reality that the disruption rarely occurs. The simulation parameters are shown in Table 3.

\begin{tabular}{|c|c|c|}
\hline Parameter Name & Notation & Value \\
\hline Production rate & $\mathrm{q}$ & 1.5 \\
\hline Demand rate & $\mu$ & 0.9 \\
\hline Demand volatility & $\sigma^{2}$ & 1.8 \\
\hline Backlog penalty cost & $\mathrm{p}$ & 10 \\
\hline Holding cost & $\mathrm{h}$ & 1 \\
\hline Switching cost & $\mathrm{k}$ & 2 \\
\hline Ordering cost & $\mathrm{b}$ & 2 \\
\hline Initial inventory level & $\mathrm{X} 0$ & 1 \\
\hline Initial raw material inventory level & $\mathrm{Y} 0$ & 5 \\
\hline Raw material reorder position & $\mathrm{r}$ & 1 \\
\hline Raw material ordering quantity & $\mathrm{Q}$ & 100 \\
\hline
\end{tabular}

Table 3. "Simulation parameters".

\subsection{Numerical results}

The simulation parameter values are shown in Table 3. Table 4 shows the effects of demand disruptions, which are considered without supplier selection options, where the optimal critical levels of $x 0$ and $x 1$ are found by the SA method. Table 4 shows that as the drop magnitude of demand increases, the long-term average cost $\mathrm{g}$ decreases from 335 to 181 . The decreased cost, which mainly comes from machine raw material ordering cost and switching cost, illustrates that due to the reduced demand, the factory production activity decreases in terms of decreased production and ordering activity. As the demand increases, the total cost increases due to the increased production and ordering activity.

It is noted that when the demand jumps downward, the optimal $x 0$ is close to the reorder point, which reflects that the lower boundary is kept close to the reorder point because of the reduced demand requirement and justifies the intuition that the production and ordering activities decrease so that the optimal production mechanism looks more passive until the raw material is almost depleted. When the 
demand jumps upward, the lower boundary increases, which implies that the inventory is kept at a relatively high level to meet the increased demand and the production activities heat up so that the optimal production mechanism looks more active. When the demand jumps downward, the difference between $x 0$ and $x 1$ is larger than that when the demand jumps upward. This implies that the wider range accounts for more uncertainties and downward jumps have more severe effect on the stability of the supply chain.

We also notice that the total cost difference between downward jumps and upward jumps comes from ordering and switching costs. The reason is that when the demand increases, the manufacturer needs to order more raw materials and keeps producing to meet the increased demand so that there will be more ordering cost. Also, the production mechanism has a greater chance to hit the boundary because of the smaller range between $x 0$ and $x 1$, leading to a higher switching cost.

In the following section, we will combine the quantitative effects of demand disruptions on the performance of the supply chain with the qualitative factors considered in supplier selection problem. In order to study the optimal supplier selection under demand disruptions, an improved Analytical Hierarchy Process (AHP) is proposed to integrate these quantitative and qualitative factors.

\begin{tabular}{|l|c|c|c|c|c|c|c|c|}
\hline Case & $\begin{array}{c}\text { Max. } \\
\text { Jump in } \\
\text { Demand }\end{array}$ & $\begin{array}{c}\text { \% of } \\
\text { variance }\end{array}$ & $\mathbf{x}_{\mathbf{0}}$ & $\mathbf{x}_{\mathbf{1}}$ & \multicolumn{5}{|c|}{ Expected cost } \\
\cline { 6 - 9 } & & & & $\begin{array}{c}\text { Inventory } \\
\text { cost }\end{array}$ & $\begin{array}{c}\text { Ordering } \\
\text { cost }\end{array}$ & $\begin{array}{c}\text { Switching } \\
\text { cost }\end{array}$ & $\begin{array}{c}\text { Total } \\
\text { cost }\end{array}$ \\
\hline 1 & 0 & 0 & 1.01 & 85.08 & 27.67 & 184 & 124 & 335.67 \\
\hline 2 & -0.1 & $-12.25 \%$ & 1.03 & 87.26 & 32.40 & 164 & 108 & 304.40 \\
\hline 3 & -0.2 & $-24.69 \%$ & 1.09 & 109.05 & 37.67 & 142 & 94 & 273.67 \\
\hline 4 & -0.3 & $-37.04 \%$ & 1.00 & 104.30 & 30.53 & 118 & 92 & 240.53 \\
\hline 5 & -0.5 & $-61.73 \%$ & 1.01 & 119.32 & 55.01 & 76 & 50 & 181.01 \\
\hline 6 & 0.1 & $12.25 \%$ & 1.01 & 71.68 & 23.39 & 208 & 138 & 369.39 \\
\hline 7 & 0.2 & $24.69 \%$ & 3.67 & 62.43 & 19.94 & 228 & 152 & 399.94 \\
\hline 8 & 0.3 & $37.04 \%$ & 2.95 & 48.99 & 24.37 & 242 & 170 & 436.37 \\
\hline 9 & 0.5 & $61.73 \%$ & 38.67 & 69.14 & 27.35 & 294 & 196 & 517.35 \\
\hline
\end{tabular}

Table 4. "Results of jump-diffusion process with various sizes".

\subsection{Supplier selection under demand disruption}

The proposed supplier selection procedure can be used for multiple suppliers' case, but only three typical types of suppliers are considered in this paper for illustration purposes. The characteristics of the suppliers are described in Table 5. Although 
the example might not exhaustively represent all the suppliers' cases, the proposed method can be applied to a wide range of applications.

Since delivery time and ordering cost are the main factors to consider in supplier selection problems, we represent the suppliers from the perspectives of delivery time and ordering cost in our study. The quantitative results can be obtained from the simulation program for different delivery time and ordering cost scenarios, Table 5 shows that if the supplier is more reliable and provides faster delivery, then its ordering cost is relatively higher. Similarly, if the supplier is less reliable and provides slower delivery, then its ordering cost is cheaper.

\begin{tabular}{|c|c|c|c|}
\hline Supplier & Reliability & $\begin{array}{c}\text { Supplier Ordering } \\
\text { Cost per time (b) }\end{array}$ & $\begin{array}{c}\text { Delivery Time } \\
\text { Units (hours) }\end{array}$ \\
\hline A & High & $\mathrm{b}=2$ & 50 \\
\hline B & Medium & $\mathrm{b}=1.5$ & 70 \\
\hline C & Low & $\mathrm{b}=1$ & 100 \\
\hline
\end{tabular}

Table 5. "Supplier characteristics description".

Using the simulation optimization procedure presented previously, we find the optimal critical values $\mathrm{x}_{0}$ and $\mathrm{x}_{1}$ and the expected cost for case 4 described in Table 4, where the maximum jump in demand is -0.3 , i.e. $-37.04 \%$ of the variance. The comparison results are shown in Table 6 . The results show that Supplier B has the lowest long-term average cost among three of them, Supplier C causes the largest long-term average cost and Supplier A has the median cost, indicating that the ordering cost is not the only factor affecting the total cost, but the delivery time affects the total cost as well, numerically justifying our intuition about the effects of delivery time on the total cost.

\begin{tabular}{|c|c|c|c|c|c|c|c|}
\hline \multicolumn{3}{|c|}{$\begin{array}{l}\text { Case 4: Max Jump in Demand is } \\
-0.3 \text {, i.e. }-37.04 \% \text { of the variance }\end{array}$} & \multicolumn{5}{|c|}{ Expected cost } \\
\hline \multirow{2}{*}{$\begin{array}{l}\text { Sup- } \\
\text { plier }\end{array}$} & \multirow[t]{2}{*}{$x_{0}$} & \multirow[t]{2}{*}{$\mathbf{x}_{1}$} & \multicolumn{2}{|c|}{ I nventory cost } & \multirow{2}{*}{$\begin{array}{l}\text { Order- } \\
\text { ing cost }\end{array}$} & \multirow{2}{*}{$\begin{array}{l}\text { Switch- } \\
\text { ing cost }\end{array}$} & \multirow{2}{*}{$\begin{array}{l}\text { Total } \\
\text { cost }\end{array}$} \\
\hline & & & Backlog cost & Holding cost & & & \\
\hline A & 1.14 & 33.18 & 5.14 & 13.32 & 118 & 232 & 398.46 \\
\hline$B$ & 4.60 & 48.99 & 2.93 & 18.26 & 88 & 234 & 343.19 \\
\hline C & 7.74 & 27.37 & 154.6 & 4.15 & 58 & 254 & 470.75 \\
\hline
\end{tabular}

Table 6. "Costs comparison for different suppliers".

Note that the difference between $x 0$ and $x 1$ for Supplier $C$ is the smallest, which is associated with the highest total cost. Because the delivery time for Supplier $C$ is the longest, the possibility of causing backlog cost is the largest, which will lead to 
the highest inventory cost. In our study it is assumed that the manufacturer wants to meet the demand as much as possible, so the penalty cost $(p=10)$ is set to be the highest compared to the holding cost $(h=1)$, switching cost $(k=2)$ and ordering cost $(0=2)$. Because of the longest lead time for Supplier $C$, the optimal lower boundary level $x 0$ is found to be the highest in order to avoid the penalty cost. Table 6 shows that Supplier $C$ has the largest backlog cost compared to those for Supplier A and B, which is the largest cost difference among holding cost, ordering cost and switching cost. Therefore, Supplier $C$ has the largest total cost due to the effects of its longest delivery time.

Although Supplier A the shortest delivery time, it does not have the least total cost, because the highest ordering cost offsets the advantages of shortest delivery time. The difference between the lower boundary $(x 0)$ and the upper boundary $(x 1)$ for Supplier B is the largest among Suppliers A, B and C, hence, the holding cost for Supplier $B$ is the largest due to the highest chance to hold inventory. Note that the optimal switching points $x 0$ and $x 1$ are searched by the simulated annealing method, which will find the best balance combination among backlog cost, holding cost, ordering cost and switching cost in order to obtain the least total cost. Although Supplier B has a longer delivery time than Supplier A and a larger ordering cost rate than Supplier $C$, the numerical results show that it has the least total cost because it has a smaller ordering cost than Supplier $A$ and a smaller backlog cost than Supplier C. This implies that Supplier B is somehow more balanced in terms of ordering cost and delivery time. Hence, for case 4, Supplier B is the best choice for the manufacturer from the perspective of total cost. Additionally, the numerical results demonstrate that a single factor does not determine the best choice, but the combination of multiple factors. For example, Supplier B has neither the least ordering cost nor the least inventory cost, but it has the least total cost.

\subsection{I mproved AHP for supplier selection}

Since there are many factors to be taken into account when selecting suppliers, we combine the results in Section 4.4 with other qualitative factors by using Analytical Hierarchy Process (AHP). As discussed in the literature review, AHP is difficult to implement under constraints. Hence, by combining the analytical results from Section 4.4, we consider not only certain qualitative factors, such as quality and 
service, but also quantitative factors, such as the total cost under demand disruptions. Thus, we will consider the supplier selection problem by using the improved AHP. Table 5 shows the three typical types of suppliers that are used in this study. These three different types are representatives of different supplier characteristics. Supplier $A$ is highly reliable, but with the highest ordering cost and shortest delivery period. Supplier $C$ is the least reliable, but with the lowest ordering cost and the longest delivery period. Supplier $B$ is more balanced. The preference level is shown in Table 7. For example, if a company moderately prefers Supplier A to Supplier B, then a value of 2 is assigned to its particular comparison. Rating for Cost criterion is defined in Equation 8.

\begin{tabular}{|c|c|}
\hline Preference Level & Numerical Value \\
\hline Equally preferred & 1 \\
\hline Moderately preferred & 2 \\
\hline Strongly preferred & 3 \\
\hline
\end{tabular}

Table 7. "Preference level".

$$
\text { Ratio }(A / B)=\operatorname{Cost}_{B} / \operatorname{Cost}_{A}
$$

Equation 8. "Cost ratio".

Three criteria for comparison ratings for each supplier are shown in Table 8, in which cost $\&$ Delivery contains quantitative information from demand disruptions, while product quality and after-sales service represent qualitative information chosen by decision-makers. The next step is to prioritize the supplier within each criterion in Table 9. The values in each column are divided by the corresponding column sum in Table 10.

\begin{tabular}{|c|c|c|c|c|c|c|c|c|c|}
\hline \multirow{2}{*}{ Supplier } & \multicolumn{3}{|c|}{ Cost \& Delivery } & \multicolumn{3}{c|}{ Quality } & \multicolumn{3}{c|}{ Service } \\
\cline { 2 - 10 } & $\mathrm{A}$ & $\mathrm{B}$ & $\mathrm{C}$ & $\mathrm{A}$ & $\mathrm{B}$ & $\mathrm{C}$ & $\mathrm{A}$ & $\mathrm{B}$ & $\mathrm{C}$ \\
\hline A & 1 & 0.86 & 1.18 & 1 & 1.1 & 1.3 & 1 & 2 & 0.8 \\
\hline B & 1.16 & 1 & 1.37 & 0.91 & 1 & 1.2 & 0.5 & 1 & 0.5 \\
\hline C & 0.85 & 0.73 & 1 & 0.77 & 0.83 & 1 & 1.25 & 2 & 1 \\
\hline
\end{tabular}

Table 8. "Supplier criteria".

\begin{tabular}{|c|c|c|c|}
\hline & \multicolumn{3}{|c|}{ Quality } \\
\hline & A & B & C \\
\hline A & 1 & 1.1 & 1.3 \\
\hline B & 0.91 & 1 & 1.2 \\
\hline C & 0.77 & 0.83 & 1 \\
\hline & 2.68 & 2.93 & 3.5 \\
\hline
\end{tabular}

Table 9. "Prioritizing Quality". 


\begin{tabular}{|c|c|c|c|c|}
\hline & \multicolumn{3}{|c|}{ Quality } & \\
\hline & A & B & C & Row Average \\
\hline A & 0.3734 & 0.3750 & 0.3714 & 0.3733 \\
\hline B & 0.3394 & 0.3409 & 0.3429 & 0.3411 \\
\hline C & 0.2872 & 0.2841 & 0.2857 & 0.2857 \\
\hline & & & & 1 \\
\hline
\end{tabular}

Table 10. "Row average for Quality".

The row averages shows the companies ranks in each criterion. The results are shown in Table 11. For example, for the Cost \& Delivery criteria, Supplier B is the most preferred, followed by Supplier A, and then Supplier C. The next step in AHP is to rank the criteria in order of importance in Table 12. Following the similar procedure, we could obtain the row averages for each criterion in Table 13.

\begin{tabular}{|c|c|c|c|}
\hline & \multicolumn{3}{|c|}{ Criteria } \\
\hline Supplier & Cost \& Delivery & Quality & Service \\
\hline A & 0.3325 & 0.3733 & 0.3705 \\
\hline B & 0.3861 & 0.3411 & 0.1997 \\
\hline C & 0.2814 & 0.2857 & 0.4298 \\
\hline
\end{tabular}

Table 11. "Supplier preferences for each criteria".

\begin{tabular}{|c|c|c|c|}
\hline Criteria & Cost \& Delivery & Quality & Service \\
\hline Cost \& Delivery & 1 & 0.9 & 1.5 \\
\hline Quality & 1.11 & 1 & 1.2 \\
\hline Service & 0.67 & 0.83 & 1 \\
\hline
\end{tabular}

Table 12. "Criteria ranking".

\begin{tabular}{|c|c|c|c|c|}
\hline Criteria & Cost \& Delivery & Quality & Service & Row Average \\
\hline Cost \& Delivery & 0.3600 & 0.3293 & 0.4054 & 0.3649 \\
\hline Quality & 0.4000 & 0.3659 & 0.3243 & 0.3634 \\
\hline Service & 0.2400 & 0.3049 & 0.2703 & 0.2717 \\
\hline & & & & 1 \\
\hline
\end{tabular}

Table 13. "Criteria weights".

An overall score for each supplier is computed by multiplying the matrix of company's preference by the matrix of criteria. Equation 9 shows the results. Note that Supplier A has the highest overall score, which is 0.3576 , and Supplier B has the lowest overall score, which is 0.3191 . Based on these scores, Supplier A should be selected. 


$$
\left[\begin{array}{l}
\text { Supplier A } \\
\text { Supplier B } \\
\text { Supplier C }
\end{array}\right]=\left[\begin{array}{lll}
0.3325 & 0.3733 & 0.3705 \\
0.3861 & 0.3411 & 0.1997 \\
0.2814 & 0.2857 & 0.4298
\end{array}\right] \times\left[\begin{array}{l}
0.3649 \\
0.3634 \\
0.2717
\end{array}\right]=\left[\begin{array}{l}
0.3576 \\
0.3191 \\
0.3233
\end{array}\right]
$$

Equation 9. "Supplier weight matrix".

From the perspective of total cost, Supplier B has the least total cost presented in Table 6. However, if the manufacturer considers other qualitative factors, such as quality and service, then Supplier A has an overall advantage over other suppliers, so it is the best choice for the manufacturer. The improved AHP can integrate the quantitative factors, such as expected long-term cost under demand disruptions, with qualitative factors, such as quality and service, to make the best decision based on a broader point of view. Note that if decision makers have different weights for different factors, their selection of supplier may change according to the weights assigned to the factors.

\section{Sensitivity analyses}

In this section, we conduct sensitivity analyses in order to obtain deeper insights of effects of demand disruptions. Firstly, by fixing critical value $x_{0}$ and $x_{1}$, we can obtain the total cost in Table 14 which shows that the total cost increases for each case in comparison to that in Table 4. This indicates that the optimal critical values could save more cost for the integrated supply chain system. Next, considering Case 5 in Table 4, we fix $x_{0}$, but change $x_{1}$ from 25 to 160. The cost structure is shown in Table 15. Figure 1 shows the graph of the total cost versus $x_{1}$.

\begin{tabular}{|c|c|c|c|c|c|c|c|c|}
\hline Case & $\begin{array}{c}\text { Max. } \\
\text { Jump in }\end{array}$ & $\begin{array}{c}\text { \% of } \\
\text { vemariance }\end{array}$ & $\mathbf{x}_{\mathbf{0}}$ & $\mathbf{x}_{\mathbf{1}}$ & \multicolumn{4}{|c|}{ Expected cost } \\
\cline { 5 - 8 } & & & $\begin{array}{c}\text { Inventory } \\
\text { cost }\end{array}$ & $\begin{array}{c}\text { Ordering } \\
\text { cost }\end{array}$ & $\begin{array}{c}\text { Switching } \\
\text { cost }\end{array}$ & $\begin{array}{c}\text { Total } \\
\text { cost }\end{array}$ \\
\hline 1 & 0 & No Jump & 1.01 & 85.08 & 27.67 & 184 & 124 & 335.67 \\
\hline 4 & -0.3 & $37.04 \%$ & 1.01 & 85.08 & 38.65 & 118 & 112 & 268.65 \\
\hline 5 & -0.5 & $61.73 \%$ & 1.01 & 85.08 & 38.91 & 74 & 86 & 198.91 \\
\hline 8 & 0.3 & $37.04 \%$ & 1.01 & 85.08 & 18.85 & 250 & 168 & 436.85 \\
\hline 9 & 0.5 & $61.73 \%$ & 1.01 & 85.08 & 140.38 & 292 & 196 & 628.38 \\
\hline
\end{tabular}

Table 14. "Total cost for fixed $\mathrm{x}_{0}$ and $\mathrm{x}_{1}$ ". 


\begin{tabular}{|c|c|c|c|c|c|}
\hline \multirow{2}{*}{$\mathbf{x}_{\mathbf{0}}$} & \multirow{2}{*}{$\mathbf{x}_{\mathbf{1}}$} & $\begin{array}{c}\text { I nventory } \\
\text { cost }\end{array}$ & $\begin{array}{c}\text { Ordering } \\
\text { cost }\end{array}$ & $\begin{array}{c}\text { Switching } \\
\text { cost }\end{array}$ & $\begin{array}{c}\text { Total } \\
\text { cost }\end{array}$ \\
\hline 1.01 & 160 & 55.07 & 76 & 50 & 181.07 \\
\hline 1.01 & 140 & 55.07 & 76 & 50 & 181.07 \\
\hline 1.01 & 119.32 & 55.01 & 76 & 50 & 181.01 \\
\hline 1.01 & 100 & 47.18 & 76 & 82 & 205.18 \\
\hline 1.01 & 85 & 38.91 & 74 & 86 & 198.91 \\
\hline 1.01 & 65 & 32.00 & 74 & 100 & 206.00 \\
\hline 1.01 & 45 & 23.85 & 74 & 134 & 231.85 \\
\hline 1.01 & 25 & 14.70 & 74 & 218 & 306.70 \\
\hline
\end{tabular}

Table 15. "Total cost for fixed $x_{0}$ in case 5 ".

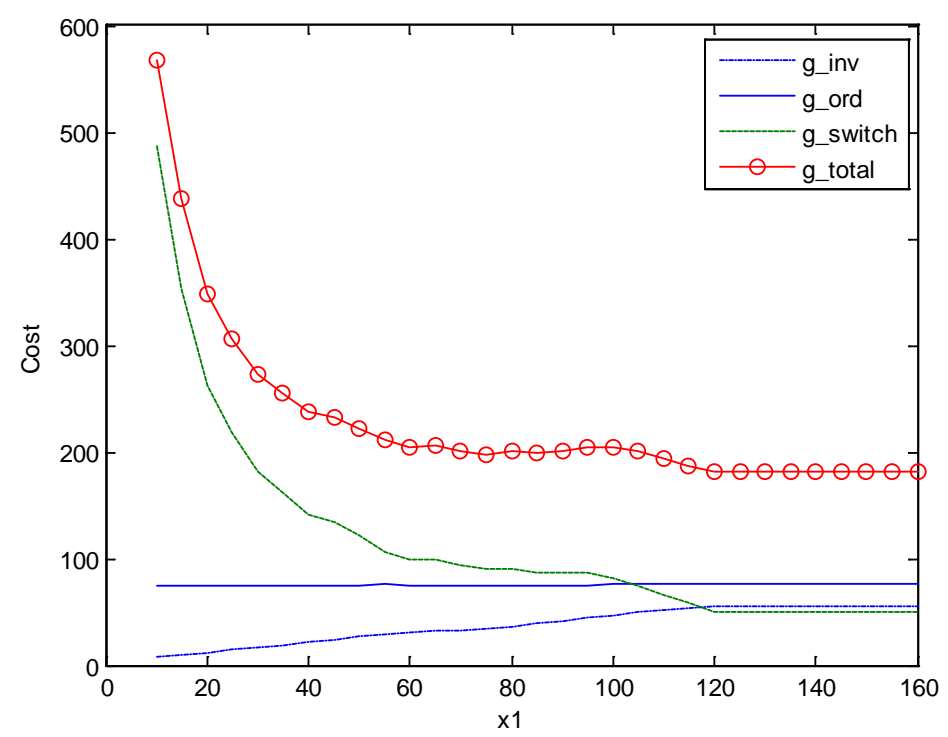

Figure 1. "Graph of the total cost for fixed $x_{0}$ in case 5".

In Figure 1, g_inv denotes the inventory cost, g_ord denotes the ordering cost, g_switch denotes the switching cost and g_total denotes the total cost. The figure shows that the total cost is declining as $x_{1}$ increases. When $x_{1}$ is between 120 and 160 , the total cost is almost the same, which indicates that $x_{1}=119.32$ is the optimal value for a minimum total cost. The figure also shows that the switching cost declines as the range of critical switching points increases, which matches our intuition that the wider the range, the less frequently the switch occurs. As $x_{1}$ increases, the inventory cost rises as the result of increasing holding cost, while the ordering cost keeps almost constant. In order to further investigate the effects of parameters' changes on the supplier selection choice, the modified supplier characteristics are summarized in Table 16, in which the delivery time is selected in a much smaller scale, while the ordering cost is kept the same. 


\begin{tabular}{|c|c|c|c|}
\hline Company & Reliability & $\begin{array}{c}\text { Supplier Ordering } \\
\text { Cost (b) }\end{array}$ & $\begin{array}{c}\text { Delivery Time } \\
\text { Units (hours) }\end{array}$ \\
\hline A & High & $\mathrm{b}=2$ & 3 \\
\hline B & Medium & $\mathrm{b}=1.5$ & 5 \\
\hline C & Low & $\mathrm{b}=1$ & 7 \\
\hline
\end{tabular}

Table 16. "Supplier characteristics comparison".

Table 17 shows that for case 4 the Supplier $C$ has the lowest total cost among three suppliers and Supplier A has the highest total cost. Note that in Table 17 the inventory costs are actually the holding costs because the backlog costs for Supplier A, B and C are almost 0 in the numerical results. In our study, the production rate is larger than the demand rate since it is assumed that the manufacturer wants to satisfy the demand as much as possible. Hence, when the delivery time among Supplier A, B and C is so small that the effects can be neglected, the difference in inventory cost is not significant compared to other cost factors. Recall that Table 6 shows Supplier $C$ has the largest inventory cost because of its longest delivery time, leading to the largest backlog cost. However, the results in Table 17 show that the ordering cost is the dominant factor in determining the best supplier while there is not much difference in the inventory cost. This implies that the delivery time indeed is an important factor, but its relative difference of length among various suppliers plays a significant role in determining the least total cost option. In addition, the difference between $\mathrm{x}_{0}$ and $\mathrm{x}_{1}$ is very close among Suppliers $\mathrm{A}, \mathrm{B}$ and $\mathrm{C}$, leading to quite close inventory costs and implying that the ordering cost is the dominant factor in determining the option with the least total cost.

\begin{tabular}{|c|c|c|c|c|c|c|}
\hline \multicolumn{3}{|c|}{$\begin{array}{l}\text { Case } 4 \text { : Max Jump in Demand is } \\
-0.3 \text {, i.e. }-37.04 \% \text { of the variance }\end{array}$} & \multicolumn{4}{|c|}{ Expected cost } \\
\hline $\begin{array}{l}\text { Sup- } \\
\text { plier }\end{array}$ & $x_{0}$ & $x_{1}$ & $\begin{array}{l}\text { I nventory } \\
\text { cost }\end{array}$ & $\begin{array}{l}\text { Ordering } \\
\text { cost }\end{array}$ & $\begin{array}{l}\text { Switching } \\
\text { cost }\end{array}$ & Total cost \\
\hline$A$ & 1.65 & 48.19 & 15.89 & 118 & 234 & 367.89 \\
\hline$B$ & 1.18 & 48.03 & 15.45 & 88.5 & 238 & 341.95 \\
\hline C & 1.76 & 48.99 & 15.99 & 59 & 234 & 308.99 \\
\hline
\end{tabular}

Table 17. "Cost comparison for changed delivery time units".

By following the same improved AHP procedures discussed in Section 4.5, Supplier $C$ has the highest overall score, which is 0.3536 . Therefore, Supplier $C$ should be selected. However, in Section 4.5, Supplier A is selected. 


$$
\left[\begin{array}{l}
\text { Supplier A } \\
\text { Supplier B } \\
\text { Supplier C }
\end{array}\right]=\left[\begin{array}{lll}
0.3061 & 0.3733 & 0.3705 \\
0.3294 & 0.3411 & 0.1997 \\
0.3645 & 0.2857 & 0.4298
\end{array}\right] \times\left[\begin{array}{l}
0.3649 \\
0.3634 \\
0.2717
\end{array}\right]=\left[\begin{array}{l}
0.3480 \\
0.2984 \\
0.3536
\end{array}\right]
$$

Equation 10. "Supplier weight matrix".

We also investigate Case 5 in Table 4, which has a larger downward demand jump size. The supplier characteristics are described in Table 5. Table 18 shows that Supplier B has the lowest long-term average cost among the three suppliers. Compared with the results in Table 6, the results show that as downward demand jump occurs, the total cost for each supplier decreases, but the total cost of Supplier $A$ has the largest decreasing amount. This implies that the demand disruption pattern will impact the total costs of different suppliers. By following the improved AHP procedures, Supplier A has the highest overall score according to Equation 11 and should be selected, the same selection decision as that in Section 4.5 .

\begin{tabular}{|c|c|c|c|c|c|c|}
\hline \multicolumn{2}{|c|}{$\begin{array}{c}\text { Case 5: Max Jump in Demand is -0.5, i.e. } \\
-61.73 \% \text { of the variance }\end{array}$} & \multicolumn{4}{|c|}{ Expected cost } \\
\hline Company & $\mathbf{x}_{\mathbf{0}}$ & $\mathbf{X}_{\mathbf{1}}$ & $\begin{array}{c}\text { Inventory } \\
\text { cost }\end{array}$ & $\begin{array}{c}\text { Ordering } \\
\text { cost }\end{array}$ & $\begin{array}{c}\text { Switching } \\
\text { cost }\end{array}$ & Total cost \\
\hline A & 4.24 & 48.99 & 21.53 & 74 & 146 & 241.53 \\
\hline B & 4.06 & 55.71 & 21.42 & 55.5 & 146 & 222.92 \\
\hline C & 1.62 & 20.83 & 26.53 & 37 & 254 & 317.53 \\
\hline
\end{tabular}

Table 18. "Cost comparison for changed demand size".

$$
\left[\begin{array}{l}
\text { Supplier A } \\
\text { Supplier B } \\
\text { Supplier } C
\end{array}\right]=\left[\begin{array}{lll}
0.3516 & 0.3733 & 0.3705 \\
0.3810 & 0.3411 & 0.1997 \\
0.2674 & 0.2857 & 0.4298
\end{array}\right] \times\left[\begin{array}{l}
0.3649 \\
0.3634 \\
0.2717
\end{array}\right]=\left[\begin{array}{l}
0.3646 \\
0.3172 \\
0.3182
\end{array}\right]
$$

Equation 11. "Supplier weight matrix".

\section{Conclusions}

This paper studies a three-echelon supply chain system which consists of suppliers, one manufacturer, and customers under demand disruptions. We model demand disruptions by using a jump-diffusion model. The objective is to minimize the total cost under different demand disruption scenarios. In order to avoid local optima, the simulated annealing algorithm is used to search the optimal critical values for a two-number production-inventory policy. Various jump scenarios are tested in our simulation study. 
Numerical studies show that the demand jump size and direction will significantly affect the performance of the whole supply chain and the decision of supplier selection and that the downward jump has a more severe effect on the stability of the supply chain system. It is also shown that delivery time and ordering cost are important factors when selecting the best supplier, but the choice could vary according to different risk scenarios.

The common AHP process could not take constraints into account. Hence, the proposed improved AHP, which combines with simulation results based on demand jump scenarios, could not only release the extent of the supplier reliability in the face of supply chain disruptions but also provide quantitative analysis for senior management for different risk scenarios. Hence, it is recommended for companies to run the "stress test" which involves estimating how the company will perform and which supplier should be selected under unusual market moves. For example, different future demand scenarios could be generated by using the jump-diffusion model and then analysis of supplier selection could be conducted by using the improved AHP process.

\section{References}

Bar-Lev, S. K., Parlar, M., \& Perry, D. (1993). Impulse control of a brownian inventory system with supplier uncertainty. Stochastic Analysis and Application, 11, 11-27.

doi: $10.1080 / 07362999308809298$

Bather, J. A. (1966). A continuous time inventory model. Journal of Applied Probability, 3, 538-549.

doi: $10.2307 / 3212137$

Beyer, D. (1994). An inventory model with wiener demand process and positive lead time. Optimization, 29, 181-193.

doi: $10.1080 / 02331939408843946$

Bhutta, K. S., \& Huq, F. (2002). Supplier selection problem: a comparison of the total cost of ownership and analytic hierarchy process approaches. Supply Chain Management, 7, 126-135.

doi: $10.1108 / 13598540210436586$ 
Cakravastia, A., \& Takahashi, K. (2004). Integrated model for supplier selection and negotiation in a make-to-order environment. International Journal of Production Research, 42, 4457-4474.

doi: $10.1080 / 00207540410001727622$

Chan, F. (2003). Interactive selection model for suppleir selection process: an analytical hierarchy process approach. International Journal of Production Research, 41, 3549-3579.

doi: $10.1080 / 0020754031000138358$

Chopra, S., \& Sodhi, M. S. (2004). Managing risk to avoid supply-chain breakdown. MIT Solan Management Review, 46, 53-61.

Degraeve, Z., \& Roodhooft, F. (1999). Effectively selecting suppliers using total cost of ownership. Journal of Supply Chain Management, 35, 5-10.

doi: 10.1111/j.1745-493X.1999.tb00050.x

Ding, H., Benyoucef, L., \& Xie, X. (2005). A simulation optimization methodology for supplier selection problem. International Journal of Computer Integrated Manufacturing, 18, 210-224.

doi: $10.1080 / 0951192052000288161$

Dohi, T., Kaio, N., \& Osaki., S. (1993). Continuous time inventory control for wiener proces demand. Computers Mathematical Application, 26, 11-22.

doi: 10.1016/0898-1221(93)90002-D

Duncan, T. E., Parsik-Duncan, B., \& Zhang, Q. (1999). Adaptive control of stochastic manufacturing systems with hidden markovian demands and small noise. IEEE transactions on Automatic Control, 44, 427-430.

doi: $10.1109 / 9.746283$

Graves, S. C., \& Keilson, J. (1981). The compensation method applied to a oneproduct production/inventory problem. Mathematics of Operations Research, 6 , 246-262.

doi: $10.1287 /$ moor.6.2.246

Hanson, F. B. (2007). Applied stochastic process and control for jump-diffusions: modeling, analysis and computation. Philadelphia: SIAM. 
Haq, A. N., \& Kannan, G. (2006). Design of an integrated supplier selection and multi-echelon distribution inventory model in a built-to-order supply chain enviroment. International J ournal of Production Research, 44, 1963-1985. doi: $10.1080 / 00207540500381427$

Harrison, J. M., \& Taylor, A. J. (1978). Optimal control of a brownian storage system. Stochastic Processes and Their Applications, 6, 179-194.

Hendricks, K. B., \& Singhal, V. R. (2005). An empirical analysis of the effect of supply chain disruptions on long-run stock price performance and equity risk of the firm. Production and Operations Management, 14, 53-68.

Kirkpatrick, S., Gelatt, C. D., \& Vecchi, M. P. (1983). Optimization by simulated annealing. Science, 220, 4598.

doi: $10.1126 /$ science. 220.4598 .671

Kou, S. G. (2002). A jump-diffusion model for option pricing. Management Science, 48, 1086-1101. doi: $10.1287 / \mathrm{mnsc} \cdot 48.8 \cdot 1086.166$

Lee, H. L., Padmanabhan, V., \& Whang, S. (1997). Information distortion in a supply chain: the bullwhip effect. Management Science, 43, 546-558.

doi: $10.1287 / \mathrm{mnsc}$. 43.4.546

Lee, H. L., So, K. C., \& Tang, C. S. (2000). The value of information sharing in a two-level supply chain. Management Science, 46, 626-643.

doi: $10.1287 / \mathrm{mnsc}$. 46.5.626.12047

Narasimhan, R., Talluri, S., \& Mahapatra, S. K. (2006). Multiproduct, multicriteria model for supplier selection with product life-cycle considerations. Decision Sciences, 37, 577-603.

doi: 10.1111/j.1540-5414.2006.00139.x

Neck, R. (1984). Stochastic control theory and operational research. European J ournal of Operational Research, 17, 283-301.

doi: 10.1016/0377-2217(84)90123-1

Puterman, M. L. (1975). A diffusion process model for a storage system. Logistics, 1, 143-159. 
Qi, X., Bard, J. F., \& Yu, G. (2004). Supply chain coordination with demand disruptions. Omega, 32, 301-312.

doi: 10.1016/j.omega.2003.12.002

Song, J. S., \& Zipkin, P. H. (1996). Inventory control with information about supply conditions. Management Science, 42, 1409-1419.

doi: $10.1287 / \mathrm{mnsc}$.42.10.1409

Suman, B., \& Kumar, P. (2006). A survey of simulated annealing as a tool for single and multiobjective optimization. Journal Of The Operaional Research Society, 57, 1143-1160.

\section{doi: 10.1057/palgrave.jors. 2602068}

Smytka, D. L., \& Clemens, M. W. (1993). Total cost supplier selection model: a case study. International Journal of Purchasing and Materials Management, 29, 42-49.

Tang, C. S. (2006). Perspectives in supply chain risk management. International Journal of Production Economics, 103, 451-488.

doi: 10.1016/j.ijpe.2005.12.006

Tomlin, B. (2006). On the value of mitigation and contingency strategies for managing supply chain disruption risks. Management Science, 52, 636-657.

doi: 10.1287/mnsc. 1060.0515

Vickson, R. (1986). A single product cycling problem under brownian motion demand. Management Science, 32, 1336-1345.

doi: $10.1287 / \mathrm{mnsc} .32 .10 .1336$

Youssef, H., Sait, S., \& Adiche, H. (2001). Evolutionary algorithms, simulated annealing and tabu search: a comparative study. Engineering Applications of Artificial Intelligence, 14, 167-181.

doi: 10.1016/S0952-1976(00)00065-8 


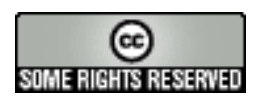

Article's contents are provided on a Attribution-Non Commercial 3.0 Creative commons license. Readers are allowed to copy, distribute and communicate article's contents, provided the author's and Journal of Industrial Engineering and Management's names are included. It must not be used for commercial purposes. To see the complete license contents, please visit http://creativecommons.org/licenses/by-nc/3.0/. 